\title{
Evaluation of the Operational Simplified Surface Energy Balance Model for Pastureland Evapotranspiration Mapping and Drought Monitoring in North Central Kentucky
}

\author{
Maheteme Gebremedhin $\mathbb{D}^{1},{ }^{1}$ Ian Ries, ${ }^{1}$ Gabriel B. Senay, ${ }^{2}$ Martin Matisoff, ${ }^{1}$ \\ Ibukun Amusan, ${ }^{3}$ Jeremy Sandifer, ${ }^{1}$ and Buddhi Gyawali ${ }^{1}$ \\ ${ }^{1}$ College of Agriculture, Communities, and the Environment, Kentucky State University, 400 East Main Street, Frankfort, \\ KY 40601, USA \\ ${ }^{2}$ United States Geological Survey, Earth Resources Observation and Science Center, \\ North Central Climate Adaptation Science Center, Boulder, CO 80303, USA \\ ${ }^{3}$ College of Business and Computational Sciences, Kentucky State University, 400 East Main Street, Frankfort, KY 40601, USA \\ Correspondence should be addressed to Maheteme Gebremedhin; maheteme.gebremedhin@kysu.edu
}

Received 19 August 2019; Revised 22 April 2020; Accepted 25 May 2020; Published 11 June 2020

Academic Editor: Nir Y. Krakauer

Copyright (C) 2020 Maheteme Gebremedhin et al. This is an open access article distributed under the Creative Commons Attribution License, which permits unrestricted use, distribution, and reproduction in any medium, provided the original work is properly cited.

\begin{abstract}
The use of remotely sensed evapotranspiration (ET) for field applications in drought monitoring and assessment is gaining momentum, but meeting this need has been hampered by the absence of extensive ground-based measurement stations for ground validation across agricultural zones and natural landscapes. This is particularly crucial for regions more prone to recurring droughts with limited ground monitoring stations. A three-year (2016-2018) flux ET dataset from a pastureland in north central Kentucky was used to validate the Operational Simplified Surface Energy Balance (SSEBop) model at monthly and annual scales. Flux and SSEBop ET track each other in a consistent manner in response to seasonal changes. The mean bias error (MBE), root mean squared error (RMSE), mean absolute percentage error (MAPE), and coefficient of determination $\left(R^{2}\right)$ were $5.47,21.49 \mathrm{~mm}$ $\operatorname{mon}^{-1}, 30.94 \%$, and 0.87 , respectively. The model consistently underestimated ET values during winter months and overestimated them during summer months. SSEBop's monthly ET anomaly maps show spatial ET distribution and its accurate representation. This is particularly important in areas where detailed surface meteorological and hydrological data are limited. Overall, the model estimated monthly ET magnitude satisfactorily and captured it seasonally. The SSEBop's functionality for remote ET estimation and anomaly detection, if properly coupled with ground measurements, can significantly enhance SSEBop's ability to monitor drought occurrence and prevalence quickly and accurately.
\end{abstract}

\section{Introduction}

Evapotranspiration (ET), the turbulent transfer of water from the ground (evaporation; E) and plant surfaces (transpiration; T), is a key component of the hydrologic cycle, which is responsible for returning $60-90 \%$ of precipitation $(P)$ to the atmosphere[1-3]. Previous studies (e.g., [4-6]) showed that ET exhibits considerable variation in space and time and, as a result, obtaining reliable and accurate measurements continues to present challenges [7]. ET is the second largest component in the terrestrial water balance $(\mathrm{ET}=P-R-S-I$, where $P=$ precipitation, $R=$ runoff, $S=$ soil storage, and $I=$ infiltration) and is the single most important predictor of seasonal crop water consumptive use drought prevalence. ET estimation and drought monitoring are determined by the availability and proliferation of remotely sensed data. Furthermore, the need for improved methods for monitoring and modeling the water cycle has fueled interest in the rapid, widespread use of remote-based ET data.

Traditional land-based ET measurements have largely relied on in situ ground observation methods, such as 
lysimtery, energy balance, Bowen ratio (FR), eddy covariance (EC), scintillometry, and soil water balance [8-12]. The surface-based EC method for small areas of coverage has proven invaluable in providing direct measurement of turbulent water vapor fluxes between the ground and the atmosphere. For more than two decades, a network of systems [11] has provided the high-quality data needed to validate remotely sensed ET estimates. The EC method directly measures ET based on statistical covariance between vertical water-vapor flux and scalar concentration fluctuations [13]. Scaling up observational ET information is a major challenge of this method because it involves a complex and multidimensional process that varies with landscape, vegetation type, soil moisture, and crop management. It is also affected by underlying environmental factors $[14,15]$. In this regard, space-borne ET estimates [16-18] are ideal to circumvent some of the stringent requirements (e.g., sensor placement and calibration) and limitations (smaller footprint) of land-based ET observations $[1,7]$.

For the past 18 years, simplified surface energy balance (SSEBop) has generated and issued ET maps for the continental United States on a monthly time interval at a $1 \mathrm{~km}$ spatial resolution scale. It also provides an efficient and timely data delivery system that is critical for operational decision-making by water resource planners and managers and hydraulic engineers. The model's use and application have successfully reported ET on different scales, i.e., watershed, basin, United States, and global scale $[19,20]$. In addition, the model has been used to generate $\mathrm{ET}_{a}$ and anomaly maps over very large extents (the coterminous United States) using low spatial resolution $(1 \mathrm{~km})$ MODIS data.

One key attribute of satellite-based ET estimate models is model validation, which is defined as the process of determining the degree to which a model is an accurate representation of the real world from the perspective of the intended uses of the model [21]. SSEBop at basin and global scales is a good example of the successful application of satellite-based ET drought monitoring [22]. SSEBop increases our understanding of the global water cycle by mapping seasonal and year-to-year changes in ET across the landscape and providing complete spatial ET coverage, supplying input data aiding simulating irrigation requirements, and assessing trends of ET. Monthly maps of actual and anomaly ET and products are available publicly via the Famine Early Warning System (https://app.climateengine. org/climateEngine).

Few studies have evaluated SSEBop across wide geographical areas (see noted exceptions [19]) and less frequently on ecosystem scales. Therefore, the goal of this study was to evaluate the performance of SSEBop in estimating ET from a pasture agroecosystem under the climate and soil conditions of north central Kentucky. Although the SSEBop model has been in use for 18 years, validation studies on its use over varied ecosystems are limited. The objectives of this study were (i) to evaluate SSEBop against EC data and its comparison to reference evapotranspiration $\left(\mathrm{ET}_{\mathrm{ref}}\right)$ as its upper boundary and (ii) to assess the application of SSEBop for drought monitoring and identifying drought years/ seasons using rainfall as a surrogate variable.

\section{Materials and Methods}

2.1. Site Microclimate. The study site is located at the Harold R. Benson Research and Demonstration Farm, $12 \mathrm{~km}$ southwest of the main campus of Kentucky State University, Frankfort, Kentucky $\left(38.11^{\circ} \mathrm{N}, 84.88^{\circ} \mathrm{W} ; 242 \mathrm{~m}\right.$ above mean sea level). The study period had marked differences in total precipitation among the years, ranging from the lowest $\left(1012 \mathrm{~mm} \cdot \mathrm{yr}^{-1}\right)$ in 2016 to $1855 \mathrm{~mm} \cdot \mathrm{yr}^{-1}$ in 2018.2018 was a 150 -year record, which gave $697 \mathrm{~mm}(60 \%)$ more rain than the historical (1980-2010) average. Based on the 30-year average of $1159 \mathrm{~mm}$ for the region, the observation years can be classified as dry in $2016(1012 \mathrm{~mm})$, average in 2017 $(1219 \mathrm{~mm})$, and wet in $2018(1855 \mathrm{~mm})$. Air temperature $\left(T_{a}\right)$ from 2016 through 2018 at the site showed no major departure relative to the thirty-year (1981-2010) average of $12.8^{\circ} \mathrm{C}$. Averaged over the three years, monthly $T_{a}$ varied between $-1^{\circ} \mathrm{C}$ in January and $24.2^{\circ} \mathrm{C}$ in July, with annual averages of $13.5,13.8$, and $13.3^{\circ} \mathrm{C}$ in 2016,2017 , and 2018 , respectively. The only exception was January 2018, which was the coldest month $\left(-5.0^{\circ} \mathrm{C}\right.$; Figure 1$)$. The soil at the site is in the well-drained McAfee silt loam soil series, commonly found in a range of 6 to 12 percent slopes, slightly acidic in $\mathrm{pH}$, and moderately drained with high permeability [23].

2.2. Pasture Management. Kentucky's pasture agroecosystem is extensive and largely rain-fed. Approximately $25 \%$ (2.5 million acres) of the total 13.4 million land area is used for pasture agroecosystems. The study area at the Harold R. Benson Research and Demonstration Farm (pasture) was seeded in 2005 and consisted of mixed grasses, predominantly fescue (Festuca arundinacea), as well as Johnson grass (Sorghum halepense), green foxtail (Setaria viridis), hemlock (Conium maculatum), common chicory (Cichorium intybus), and red clover (Trifolium pratense). During the observation years, the same mix of grass species was used and meat goats rotationally and intermittently grazed the pasture for a maximum of two weeks beginning in late June through late summer (August). Grazing was allowed until the stub height reached $0.1 \mathrm{~m}$.

2.3. Latent and Sensible Heat Measurements. Vertical exchange of $\mathrm{H}_{2} \mathrm{O}$ vapor, sensible heat, and latent heat were measured using the EC technique. The EC flux tower is located on a pasture with a sufficiently wide and horizontal fetch of at least 200-300 $\mathrm{m}$ in the major wind (westerly and southwesterly) direction. The EC tower was instrumented with a fast-response 3D sonic anemometer (WindMaster Pro; Gill Instruments, Lymington, Hampshire, UK) that measures wind speed $\left(\mathrm{m} \mathrm{s}^{1}\right)$ and sonic air temperature $\left(T_{s}\right.$, ${ }^{\circ} \mathrm{C}$ ). The wind sensor is located $2.82 \mathrm{~m}$ above the ground level. Water vapor concentration was measured in situ using a closed path infrared $\mathrm{CO}_{2} / \mathrm{H}_{2} \mathrm{O}$ gas analyzer (LI-7200; LICOR Inc., Lincoln, NE, USA). The two sensors are installed such that they are within the mixed surface layer, i.e., 


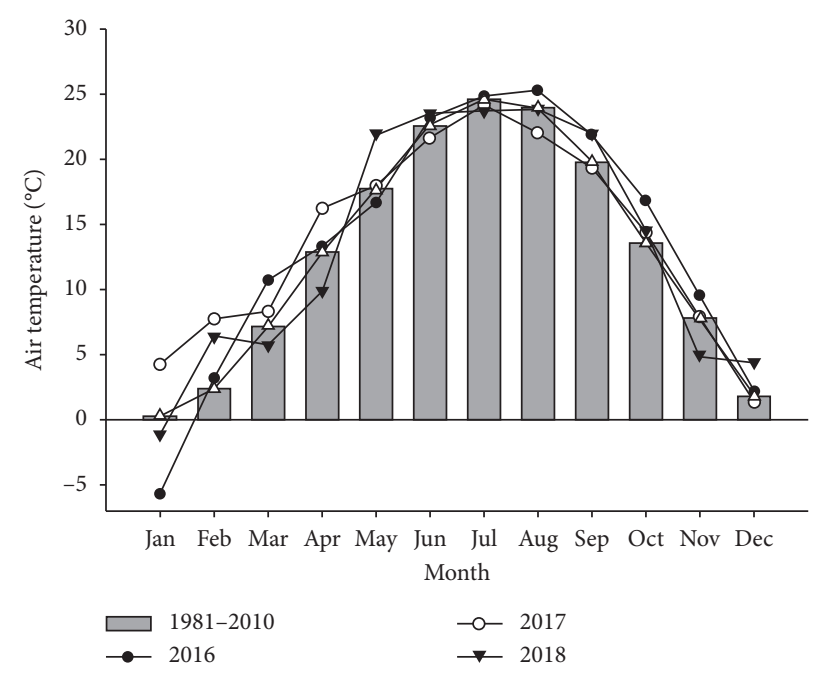

(a)

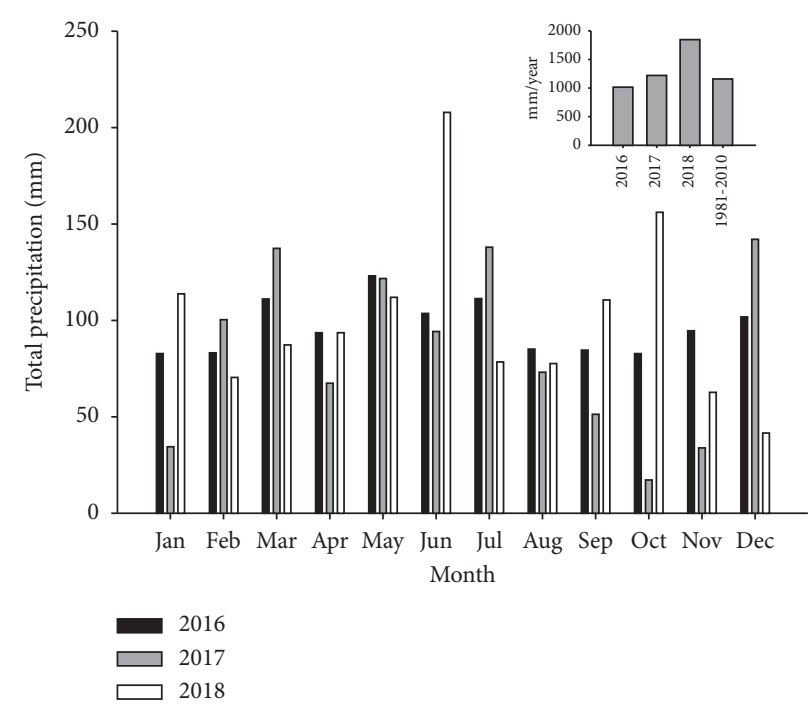

(b)

Figure 1: Average air temperature $\left({ }^{\circ} \mathrm{C}\right)$ (a) and monthly annualized precipitation $(\mathrm{mm})$ (b) at the Harold R. Benson Research and Demonstration Farm for the observation period of 2016-2018. Precipitation records are from the Franklin County Mesonet Weather Data (Lat: $38: 12^{\circ} \mathrm{N}$; Lon: $-84.88^{\circ} \mathrm{W}$, which is located about $670 \mathrm{~m}$ from the flux station. Long-term (normal, gray bars) data are from the National Weather Service Capital City Airport, Station no. US W00053841 (Lat: $38.1847^{\circ} \mathrm{N}$; Lon: $-84.9033^{\circ} \mathrm{W}$ ) (National Oceanic and Atmospheric Administration, National Environmental Satellite Data and Information Service (NOAA/NCDC)) (https://gis.ncdc.noaa.gov/maps/ncei/ normals)) [24].

$z_{h}>5 z_{m}+d$, where $z_{h}$ is the measurement height $(\mathrm{m}), z_{m}$ is the surface roughness length $(\mathrm{m})$, and $d$ is the zero plane displacement height $(\mathrm{m}$; the theoretical height above the ground where the logarithmic wind profile vanishes to zero). The measurement height $z_{h}$ was nearly 9 times the average $z_{h}$ of the grass canopy height $(0.30 \mathrm{~m}$ at peak developmental stage).

The turbulent sensible $(H)$ heat flux was computed as follows:

$$
H=\rho_{a} C_{P} \overline{w^{\prime} T_{s}^{\prime}},
$$

where $\rho_{a}$ is dry air density $\left(\mathrm{kg} \mathrm{m}^{-3}\right)$ and $C_{p}$ is the specific heat capacity of the air at constant pressure $\left(1004 \mathrm{~J} \mathrm{~kg}^{-1} \mathrm{~K}^{-1}\right)$. The overbar indicates the averaging period, in this case $30 \mathrm{~min}$. Similarly, latent heat (LE, $\mathrm{W}^{-2}$ ) was calculated as

$$
\mathrm{LE}=\lambda \overline{w^{\prime} q^{\prime}},
$$

where $\lambda$ is the latent heat of vaporization $\left(2.45 \mathrm{MJ} \cdot \mathrm{kg}^{-1}\right)$ and $q^{\prime}$ is the fluctuation about the mean of density of water vapor $\left(\mathrm{kg} \mathrm{m}^{-3}\right), \rho_{w}$, in air $\left(1000 \mathrm{~kg} \mathrm{~m}^{-3}\right)$, and $w \prime$ and $q^{\prime}$ are the turbulent vertical wind speed $(\mathrm{m} / \mathrm{s})$ and water vapor density $\left(\mathrm{kg} \mathrm{m}^{-3}\right)$, respectively. Overbar indicates the averaging period, which in this case was $30 \mathrm{~min}$. Daily ET ( $\mathrm{mm} /$ day) was estimated using the following relationship:

$$
\mathrm{ET}=\frac{\mathrm{LE}}{\rho_{w} \lambda} \text {. }
$$

Daily LE totals were calculated by integrating the 30 minute observations.

The energy balance at a surface can be thought of as accounting of energy gains and losses within a specified time interval (e.g., $30 \mathrm{~min}$, daily, monthly, seasonally, and annually). We assessed the relative energy balance by plotting the sum of $H$ and $L E$ against the available energy (i.e., $R_{n}-G$ ) and the mathematical expression for a complete energy closure assumes

$$
y+a\left(R_{n}-G\right)=H+\mathrm{LE}+G+\varepsilon,
$$

where $a$ and $y$ are the slope and intercept of the linear regression, respectively, and $G$ is ground heat flux. Unit for $R_{n}$, $G$, LE, and $H$ terms is $\mathrm{W} \cdot \mathrm{m}^{-2}$. The last term, $\varepsilon$, is the error term, which includes both instruments and random errors. $G$ was directly measured using a soil heat plate at a $10-\mathrm{cm}$ depth.

2.4. Penman-Monteith $(P-M)$ Method. Reference evapotranspiration $\left(\mathrm{ET}_{\text {ref }}, \mathrm{mm} / \mathrm{d}\right)$ measures the rate at which water vapor is released from actively growing vegetation (typically, grass height of vegetation is assumed to be $0.12 \mathrm{~m}$ ) unlimited by water with a fixed crop surface resistance of $70 \mathrm{~s} \cdot \mathrm{m}^{-1}$ and an albedo of $0.23[25,26]$. The FAO-56 (Food and Agriculture Organization) Penman-Monteith $(P-M)$ method is currently considered as the standardized method of computing reference ET from an assumed uniform grass reference surface worldwide [26]. The method computes reference evapotranspiration as daily totals $\left(\mathrm{mm} \mathrm{day}^{-1}\right)$ using the following equations:

$$
\begin{aligned}
\mathrm{ET}_{0} & =\frac{0.408 \Delta\left(R_{n}-G\right)+\gamma(900 /(T+273)) u_{2}\left(e_{s}-e_{a}\right)}{\Delta+\gamma\left(1+0.34 u_{2}\right)}, \\
\Delta & =\frac{0.4098 \times[0.6108 \times \exp ((17.27 T / T+237.3))]}{(T+237.3)^{2}},
\end{aligned}
$$


where $\Delta$ is the slope of the saturation vapor pressure function $\left(\mathrm{kPa} /{ }^{\circ} \mathrm{C}\right), R_{n}$ is the daily average net radiation (MJ $\left.\mathrm{m}^{-2} \mathrm{~d}^{-1}\right), G$ is the daily average ground heat flux (MJ $\left.\mathrm{m}^{-2} \mathrm{~d}^{-1}\right), \gamma$ is the psychometric constant $\left(\mathrm{kPa} /{ }^{\circ} \mathrm{C}\right), T$ is the daily average temperature $\left({ }^{\circ} \mathrm{C}\right), u_{2}$ is horizontal daily average wind speed $\left(\mathrm{m} \mathrm{s}^{-1}\right), e_{s}$ is the vapor pressure of the air at saturation $(\mathrm{kPa})$, and $e_{a}$ is the actual vapor pressure $(\mathrm{kPa})$.

2.5. Operational Simplified Surface Energy (SSEBop) Model. A SSEBop model was used in this study as described by Senay et al. The model uses two data streams acquired from MODIS and Global Data Assimilation Systems (GDAS) which include elevation $(z)$, temperature correction coefficient $(c)$, land surface $\left(T_{s}\right)$ and air $\left(T_{a}\right)$ temperatures, temperature difference $(\mathrm{dT})$, clear sky net radiation $\left(R_{n}\right)$, reference $\mathrm{ET}\left(\mathrm{ET}_{o}\right)$, aerodynamic resistance $\left(r_{\mathrm{ah}}\right)$, albedo $(\alpha)$, and Normalized Difference Vegetation Index (NDVI) as input variables [22]. The SSEBop directly solves for ET without explicitly resolving the other energy terms. A noteworthy feature of the model is that, for any given pixel being analyzed, the model uses two boundary surface temperature conditions (the hot and cold pixel approach) to scale LST values linearly between 0 and max ET fraction. Such codification would then permit the use of the linearization assumption by taking into account the fact that latent heat (LE) varies according to a linear function of the "hot" and "cold" pixels. Hence, the variable dT is assumed to remain constant from year to year and is typically calculated under clear sky conditions for each pixel and is derived as

$$
\mathrm{dT}=\frac{R_{n} * r_{\mathrm{ah}}}{p_{a} * C_{p}},
$$

where $R_{n}$ is the daily cloud-free net radiation (J $\left.\mathrm{m}^{-2} \mathrm{~s}^{-1}=\mathrm{W} \cdot \mathrm{m}^{-2}\right), r_{\mathrm{ah}}$ is aerodynamic resistance to sensible heat transfer from bare and dry surface with constant value of $110 \mathrm{~s} \mathrm{~m}^{-1}$ [22], and $p_{a}$ and $C_{p}$ are density of air $\left(\mathrm{kg} \mathrm{m}^{-3}\right)$ and specific heat of air at constant pressure $\left(1.013 \mathrm{~kJ} \cdot \mathrm{kg}^{-1} \cdot \mathrm{k}^{-1}\right)$, respectively. In this case, cold temperature pixels $\left(T_{c}=C * T_{\max }\right)$ are those from which there is little or no sensible heat flux, while hot temperature pixels $\left(T_{h}=T_{\text {cold }}+\mathrm{dT}\right)$ are described as those with little or no latent heat flux $\left(T_{c}\right)$. The SSEBop does not solve all energy balance components; rather it sets limited boundary conditions based on clear-sky net radiation balance principles $[20,22]$ and the only data required are surface temperature $\left(T_{s}, K\right)$, air temperature $\left(T_{a}, K\right)$, and potential ET. With this simplification, the model computes actual evapotranspiration $\left(\mathrm{ET}_{a}\right)$ as a fraction of the $\mathrm{ET}_{o}$; that is,

$$
\mathrm{ET}_{a}=\frac{p_{a} * C_{p}}{R_{n} * r_{a h}}\left(T_{h}-T_{s}\right) * k * \mathrm{ET}_{o}=\mathrm{ET}_{f} \times k \times \mathrm{ET}_{o},
$$

where $k$ is a scaling coefficient applied for $\mathrm{ET}_{o}$ to achieve a theoretical maximum set for an optimally grown alfalfa. The model uses inputs to produce anomaly maps, calculated as the arithmetic median ET deviation of a target year for measuring drought occurrence, which has a great deal of interest for geographical areas prone to drying. For a detailed and full description of the model, its application, and performance in estimating ET, please see [22, 27].

2.6. Monthly SSEBop Anomaly. To develop ET-modeled anomaly maps for the site and surrounding regions for each area considered in the study, the following steps were followed: (i) monthly averages were calculated; (ii) individual monthly anomaly of respective years was then calculated as percent difference of each year from the previous 18 years' average value using

$$
\mathrm{ET}_{m}=\left(\frac{\left(\mathrm{ET}_{a}-\mathrm{ET}_{L}\right)}{\mathrm{ET}_{L}}\right) \times 100,
$$

where $\mathrm{ET}_{m}$ is the respective monthly percent anomaly, $\mathrm{ET}_{a}$ is the monthly climatology parameter, and $\mathrm{ET}_{L}$ is the longterm ET average.

2.7. Statistical Measures of Model Fitness. As part of the validation and accuracy test, we used several statistical metrics to evaluate the SSEBop model fitness, or lack thereof, to the observed ET. A simple regression model of the form $y_{i}=a x_{i}+b$, where $y_{\mathrm{i}}$ is model $\mathrm{ET}_{o}, x_{i}$ are measured $\left(\mathrm{ET}_{m}\right)$ values, and $b$ is an intercept, was used to assess model fitness. The monthly and yearly estimates of SSEBop ET modeled values were quantitatively evaluated by percent bias (PBIAS), root mean square (RMSE), and coefficient of determination $\left(R^{2}\right)$, which were defined as

$$
\begin{aligned}
\mathrm{RMSE} & =\sqrt{\frac{1}{N} \sum_{i=1}^{N}\left(\mathrm{ET}_{m, i}-\mathrm{ET}_{e, i}\right)^{2},} \\
\mathrm{PBIAS} & =\frac{\sum_{i=1}^{n}\left(\mathrm{ET}_{i}-\mathrm{ET}_{i}\right)}{\sum_{i=1}^{n} \mathrm{ET} m, i} \times 100, \\
R^{2} & =\left[\frac{\sum_{i=1}^{N}\left(\mathrm{ET}_{m, i}-\overline{\mathrm{ET}_{m}}\right)-\left(\mathrm{ET}_{e, i}-\overline{\mathrm{ET}_{e}}\right)}{\sqrt{\sum_{i=1}^{N}\left(\mathrm{ET}_{m, i}-\overline{\mathrm{ET}_{m}}\right)^{2} \sum_{i=1}^{N}\left(e-\overline{\mathrm{ET}_{e}}\right)^{2}}}\right]^{2},
\end{aligned}
$$

where $N$ is the number of observations and $\mathrm{ET}_{o}$ and $\mathrm{ET}_{m}$ are observed (measured) and modeled ET, respectively. Smaller RMSE values indicate the closeness of model fit to the observed ET. Positive PBIAS values indicate a bias toward underestimation and negative values indicate a bias toward overestimation. $R^{2}$ values range from 0 to 1 , with values near 1 indicating better fit (or stronger power of the input variable).

\section{Results}

3.1. Description of Daily, Monthly, and Annual ET Values. Table 1 shows descriptive statistics of measured (EC), remotely SSEBop estimated, and reference evapotranspiration $(P-M)$ over a period of three years. Daily measured ET ranged between 0.026 and $5.39 \mathrm{~mm} \cdot \mathrm{day}^{-1}$ and averaged 1.88 , 1.63, and $1.49 \mathrm{~mm} \cdot \mathrm{day}^{-1}$ in 2016, 2017, and 2018, respectively (Table 1 and Figure 2). Measured monthly rates 
TABLE 1: Descriptive monthly statistics of evapotranspiration (mean \pm SEM, range, minimum (min), maximum (max), and sum of ET measured (EC, eddy covariance), simplified surface energy balance (SSEBop) model, and reference Penman-Monteith $(P-M)$ evapotranspiration) for 2016, 2017, and 2018.

\begin{tabular}{|c|c|c|c|c|c|c|}
\hline & & Mean \pm SEM $^{*}$ & Range & Min & Max & Sum \\
\hline \multirow{3}{*}{2016} & EC & $57.37 \pm 12.21$ & 111.83 & 5.24 & 117.07 & 688.46 \\
\hline & SSEBop & $55.30 \pm 15.75$ & 131.00 & 0.00 & 131.00 & 663.50 \\
\hline & $P-M$ & $102.0 \pm 9.44$ & 104.54 & 45.87 & 150.41 & 1223.95 \\
\hline \multirow{3}{*}{2017} & EC & $49.67 \pm 10.94$ & 99.16 & 2.53 & 101.69 & 596.00 \\
\hline & SSEBop & $55.54 \pm 15.03$ & 128.40 & 0.00 & 128.40 & 666.45 \\
\hline & $P-M$ & $109.08 \pm 13.34$ & 176.80 & 47.01 & 176.80 & 1308.97 \\
\hline \multirow{3}{*}{2018} & EC & $45.52 \pm 10.90$ & 98.39 & 3.21 & 101.60 & 546.18 \\
\hline & SSEBop & $57.42 \pm 15.09$ & 129.0 & 0.00 & 129.00 & 689.00 \\
\hline & $P-M$ & $89.77 \pm 12.55$ & 134.08 & 11.21 & 145.29 & 1077.28 \\
\hline
\end{tabular}

${ }^{*} \mathrm{SEM}=$ standard error of the mean.

averaged $\quad 57.37 \pm 12.21, \quad 49.67 \pm 10.94, \quad$ and $45.52 \pm 10.90 \mathrm{~mm} \cdot$ month $^{-1}$ (mean $\pm \mathrm{SEM}$ ) varying between 5.2 and 117, 2.5 and 102, and 3.2 and $102 \mathrm{~mm} \cdot \mathrm{month}^{-1}$ in 2016, 2017, and 2018, respectively. Annual measured cumulative ET were 688, 596, and $546 \mathrm{~mm} \cdot \mathrm{yr}^{-1}$ in 2016, 2017, and 2018, respectively, with corresponding annual precipitations of 1012,1220 , and $1856 \mathrm{~mm}$, respectively. The resulting $\mathrm{ET} / P$ ratios for the three years were $0.68,0.49$, and 0.29 for 2016, 2017, and 2018, respectively, depicting a relatively dry year (2016) and an abnormally wet year (2018). Estimated monthly SSEBop ranged between 0.0 and 131, 0.0 and 128.4 , and 0.0 and $129 \mathrm{~mm} \mathrm{mon}^{-1}$ in 2016, 2017, and 2018, respectively, with monthly average values of $55.29 \pm 15.75, \quad 55.54 \pm 15.03$, and $57.42 \pm 15.09$ (mean\pm SEM) for 2016, 2017, and 2018, respectively. Estimated annualized totals of SSEBop were 664, 666, and $689 \mathrm{~mm} \cdot$ year $^{-1}$ in 2016, 2017, and 2018, respectively. Reference evapotranspiration based on the physical PenmanMonteith $(P-M)$ equation revealed much wider ranges: between 0.16 and $6.7 \mathrm{~mm} \cdot \mathrm{day}^{-1} \quad\left(3.2 \pm 0.08 \mathrm{~mm} \cdot \mathrm{day}^{-1}\right.$; mean \pm SEM), 0.3 and $8.4 \mathrm{~mm} \cdot$ day $^{-1}\left(3.6 \pm 0.09 \mathrm{~mm} \cdot\right.$ day $\left.^{-1}\right)$, and 0.2 and $6.4 \mathrm{~mm} \cdot \mathrm{day}^{-1}\left(2.9 \pm 0.08 \mathrm{~mm} \cdot \mathrm{day}^{-1}\right)$ in 2016, 2017, and 2018, respectively (Figure 2, top).

Estimates of monthly satellite-derived ET by SSEBop ranged from 0 to $131 \mathrm{~mm} \cdot \mathrm{month}^{-1}$ (Table 1 ) and averaged $56.1 \pm 15.3 \mathrm{~mm} \cdot$ year $^{-1}$ across the observation period. The SSEBop model overestimated the actual ET $(50.1 \pm 15.3 \mathrm{~mm})$ by nearly $5.5 \mathrm{~mm}(12 \%)$. Similarly, SSEBop's yearly ET sums were 663,666 , and $689 \mathrm{~mm} \cdot$ year $^{-1}$ for 2016, 2017, and 2018, respectively (average: $673 \mathrm{~mm} \cdot \mathrm{year}^{-1}$ ). Summed across the three years, the SSEBop model overestimated ET by $192 \mathrm{~mm}$ over the measured ET (EC method). In each year, the median measured ET (EC) increased between January and June and declined thereafter with slight variation from year to year (Figure 2, bottom). Median (EC) evapotranspiration flux ranged between 0.3 (January) and $4.3 \mathrm{~mm} \cdot$ day $^{-1}$ (June).

3.2. Assessment of SSEBop Performance. To evaluate the accuracy of the modeled ET estimates at monthly scale, performance indices including coefficient of correlation $\left(R^{2}\right)$, root mean square error (RMES) and mean absolute error (MAE), and percent bias (PBIAS) were used (Table 2). Broadly, SSEBop showed a tendency to overestimate monthly ET flux, exhibiting BIAS, RMSE, MAPE, MRE, and $R^{2}$ of $5.47,21.5,30.9,10.5$, and 0.87 , respectively.

Although the model (SSEBop) consistently tracked measured $\mathrm{ET}_{m}$, with higher than measured flux values, moderate mismatches existed on monthly scales (Figure 3). Differences between the modeled and measured values were greatly pronounced (under- or overestimated) at two critical phases of the ET cycle during the peak ET summer months and winter months but there was a satisfactory agreement during fall and spring months. As expected, both measured and modeled values followed the natural seasonal pattern of ET, consistent with the cooling (winter, low ET) and warming (summer, high ET). Obviously, the model exhibited a level of bias, but it did track the expected ET trend as a whole. The RMSE test set was within 150.64, 100, and $100 \mathrm{~mm}$ of the measured ET for 2016, 2017, and 2018, respectively. Substantial variations existed among months (within a year) and among years between $P-M$ and flux: $\mathrm{BIAS}=49.5, \mathrm{RMES}=56.7, \mathrm{MAPE}=95.5, \mathrm{MRE}=94.9, R^{2}$, and $\mathrm{CV}=0.39$. As shown in Figure 3, SSEBop tended to overestimate ET particularly during the summer months.

As expected, the performance of the $P-M$ physical model at this pasture site was not as good as the performance of the SSEBop model at estimating monthly ET (Table 2). Figure 4 shows the scatter plots between SSEBop and measured ET values with the 95\% confidence intervals $\left(R^{2}=0.90\right)$. Regression analysis indicated that the slope of the regression line did not statistically differ $(P<0.0001)$ from 0 , suggesting good performances of the remote SSEBop model in estimating ET. Underpredictions suggested that the SSEBop model provided relatively conservative (lower ranges) estimates during the winter. This consistent pattern (i.e., overestimates at the high ET end and underestimates at low ET) may be associated with the inability of the model to fully capture ET fluxes from slowly growing grass during the winter months. Although the underestimation in winter could be offset by overestimation in other seasons (particularly during the summer growing season), the annual ET models values tended to be clustered around $673 \mathrm{~mm} \cdot \mathrm{year}^{-1}$ versus the measured value of $609 \mathrm{~mm} \cdot \mathrm{year}^{-1}$.

3.3. ET Anomaly Maps. Figure 5 presents annual ET (estimated) monthly anomaly maps for the period between 2016 


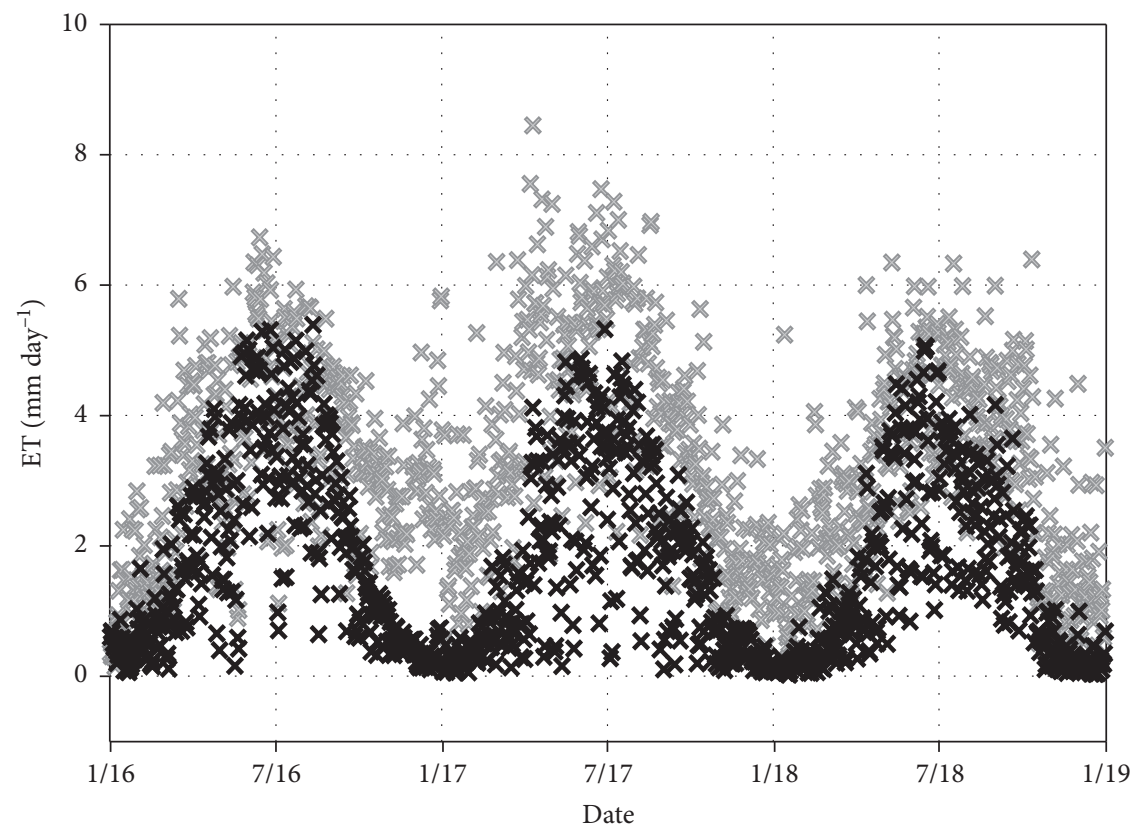

$x$ Reference ET $(P-M)$

$\times$ Measured ET (EC)

(a)

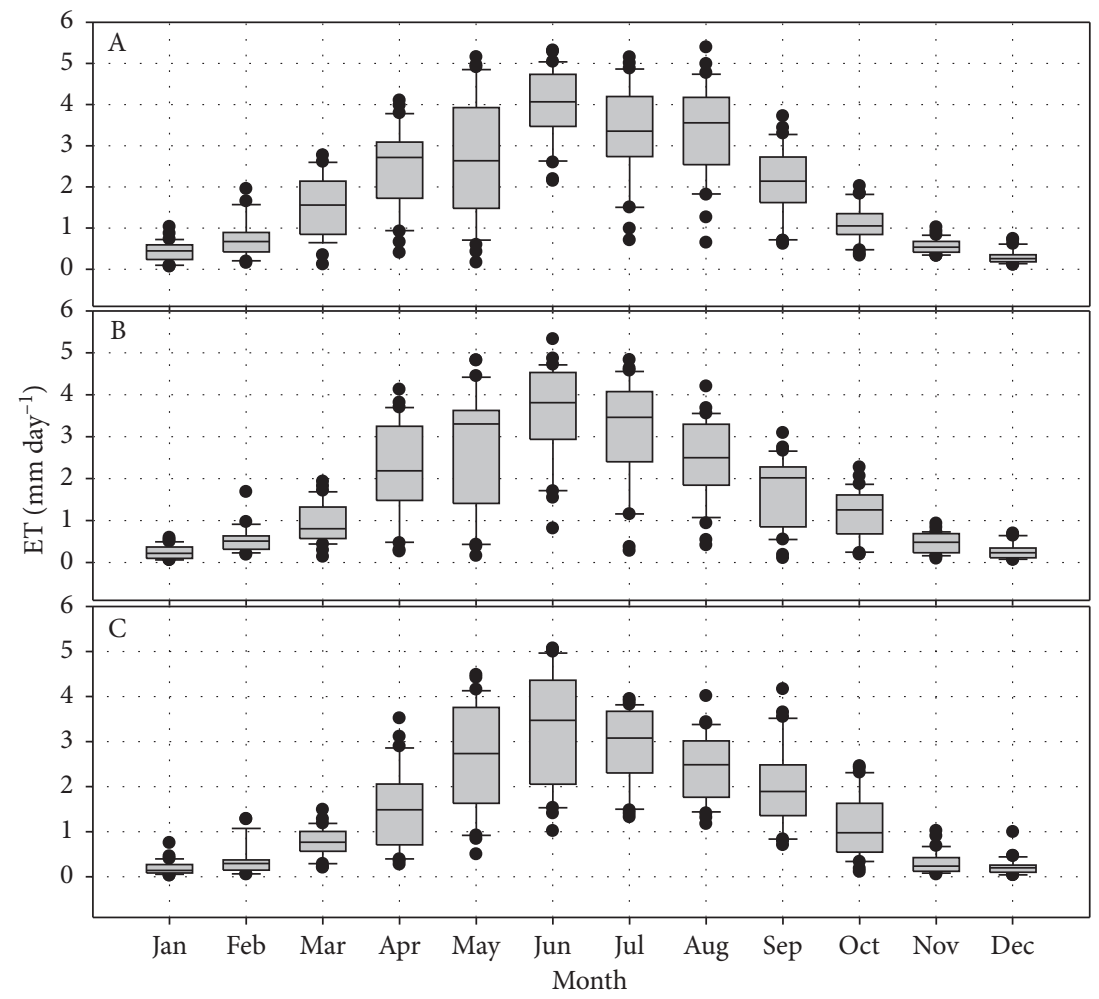

(b)

FIgURe 2: (a) Daily rates ( $\mathrm{mm} \mathrm{day}^{-1}$ ) of measured (black) evapotranspiration flux (EC) and reference Penman-Monteith ( $P-M$ ) evapotranspiration. (b) Median daily measured evapotranspiration rate $\left(\mathrm{mm}\right.$ day ${ }^{-1}$ ) for each month by year. Boxes bounding the inner quartiles and whiskers indicate 50\% and 95\% of the median values of ET. A: 2016. B: 2017. C: 2018. 
TABle 2: Performance indices used to compare estimated monthly ET (SSEBop) and Penman-Monteith $(P-M)$ against flux measured ET.

\begin{tabular}{lccccc}
\hline & BIAS & RMSE & MAPE & MRE & $R^{2}$ \\
\hline SSEBop & 5.47 & 21.49 & 30.94 & 10.48 & 0.87 \\
$P-M$ & 49.55 & 56.76 & 95.51 & 94.90 & 0.60 \\
\hline
\end{tabular}

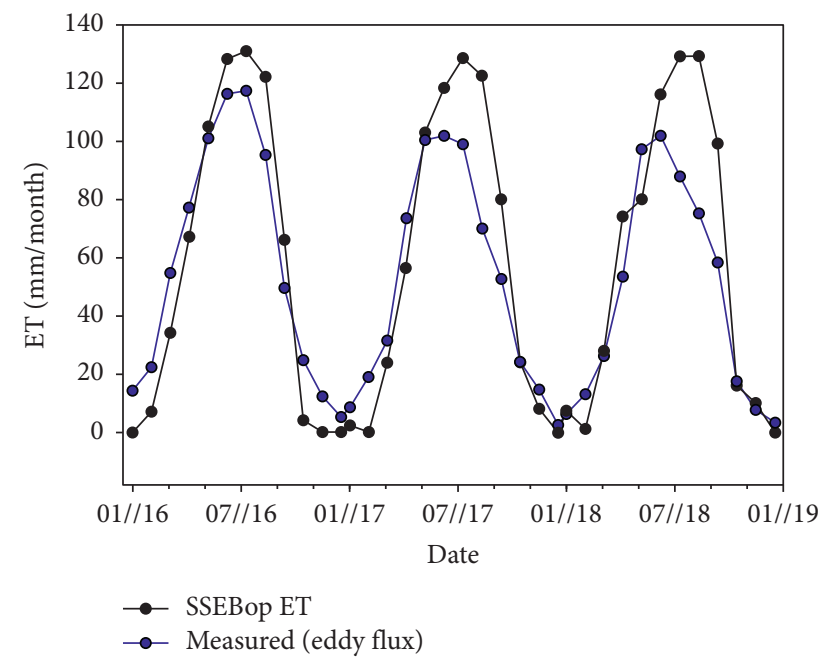

FIGURE 3: Monthly total ( $\mathrm{mm} \mathrm{month}{ }^{-1}$ ) estimated by SSEBop (black) and measured ET (blue) during 2016-2018.

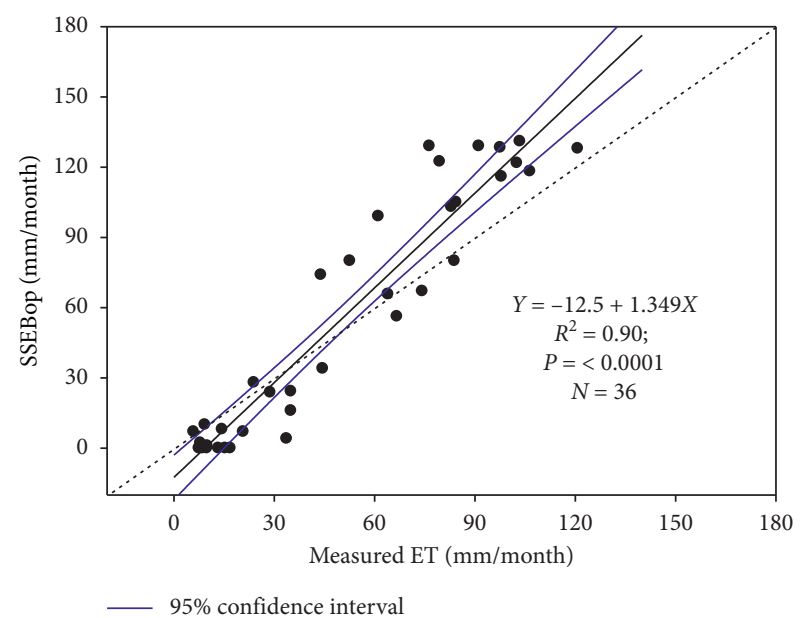

FIGURE 4: Monthly (mm/month) evapotranspiration (ET; $x$-axis) plotted against estimated ET by the SSEBop ( $y$-axis) at pasture flux tower location site during 2016-2018. Model performances are assessed using coefficient of determination $\left(R^{2}\right)$. Also shown are the 1 : 1 (dashed line), regression line (solid line), and 95\% CI (blue lines).

and 2018. ET anomalies over our measurement area and surrounding regions are shown on a monthly scale. Although severe drought did not occur during the observation years, the anomaly maps show mild drought conditions in 2016 compared to the wetter 2018. The above average precipitation during 2018 resulted in a strong ET positive anomalies (especially in July and August), but the monthly maps depict water deficiency from the drought in 2016 when the rainfall deficit was relatively large (i.e., 2017 and 2018; Figures 6 and 5).

\section{Discussion}

In this study, we evaluated SSEBop's ET monthly estimates against observed data (from an eddy covariance flux station) over a pastureland site in north central Kentucky. Overall, the SSEBop monthly estimates were highly correlated and tracked well with seasonal data. We found month-to-month bias ( $\sim 5 \mathrm{~mm} / \mathrm{month})$ that led to a pattern of overestimation in the warmer months or underestimation in the cooler months. Such bias could likely impact the magnitude of the estimated ET. On the other hand, a high correlation (e.g., low $R^{2}$ ) between modeled and true concentrations is indicative of a high degree of association. We found that while the model captures the temporal variability of ET, month-tomonth differences were evident. Notable was the fact that SSEBop quantitative ET estimates tend to underestimate ET during cooler months. This probably could be attributed to strong cloud attenuation effects of the main winter rainy months. Such underestimation of $\mathrm{ET}_{a}$ occurs when the ET fraction $\left(\mathrm{ET}_{f}=\mathrm{ET}_{a} / \mathrm{kET}_{o}\right)$ is small [19]. Noted differences between the observed and estimated values during the wet and dry months may stem from the key assumption the model makes in that differences in land surface temperature (LST) over a homogeneous landscape are primarily due to differences in vegetation and functional differences in water use. The model also ignores the contribution of albedo (canopy reflectance) and ground heat flux as part of the ET estimation.

The close correspondence between SSEBop estimates demonstrates the promise of satellite-sensed ET approaches to remotely monitor crop water use and drought conditions at plot scales in contrasting precipitation years. The SSEBop model ET estimates have previously been validated using networked eddy covariance data flux station at watershed and regional scales, mainly in western United States [19] and to a lesser degree in the southeastern US.

Whereas space-based estimates, such as the MODIS and SSEBop, are the most promising with regard to spatial and temporal resolution of ET products, retrieval quality is strongly tied to the algorithm's ability to detect and screen cloud interference, reduce the attenuation and scattering effects arising from cloud shadow [27], and hence improve the values of the interpolated pixels [28]. These and the next generation of future advances in retrieval procedures will enhance space-based realistic descriptions of the spatial distribution of ET.

This contrasting anomaly indicates the dependency of ET on precipitation and on soil moisture availability. In the past, SSEBop anomaly maps showed and clearly captured two major drought events that engulfed much of the southeastern United States during the 2007 and 2012 extreme droughts. Drought, as a consequence of soil moisture deficiency, causes an increase in ET anomalies by reducing evaporative (latent heat) fluxes. One of the advantages of estimating ET remotely is to be able to provide anomaly maps for decision-makers in response to emergencies, such 


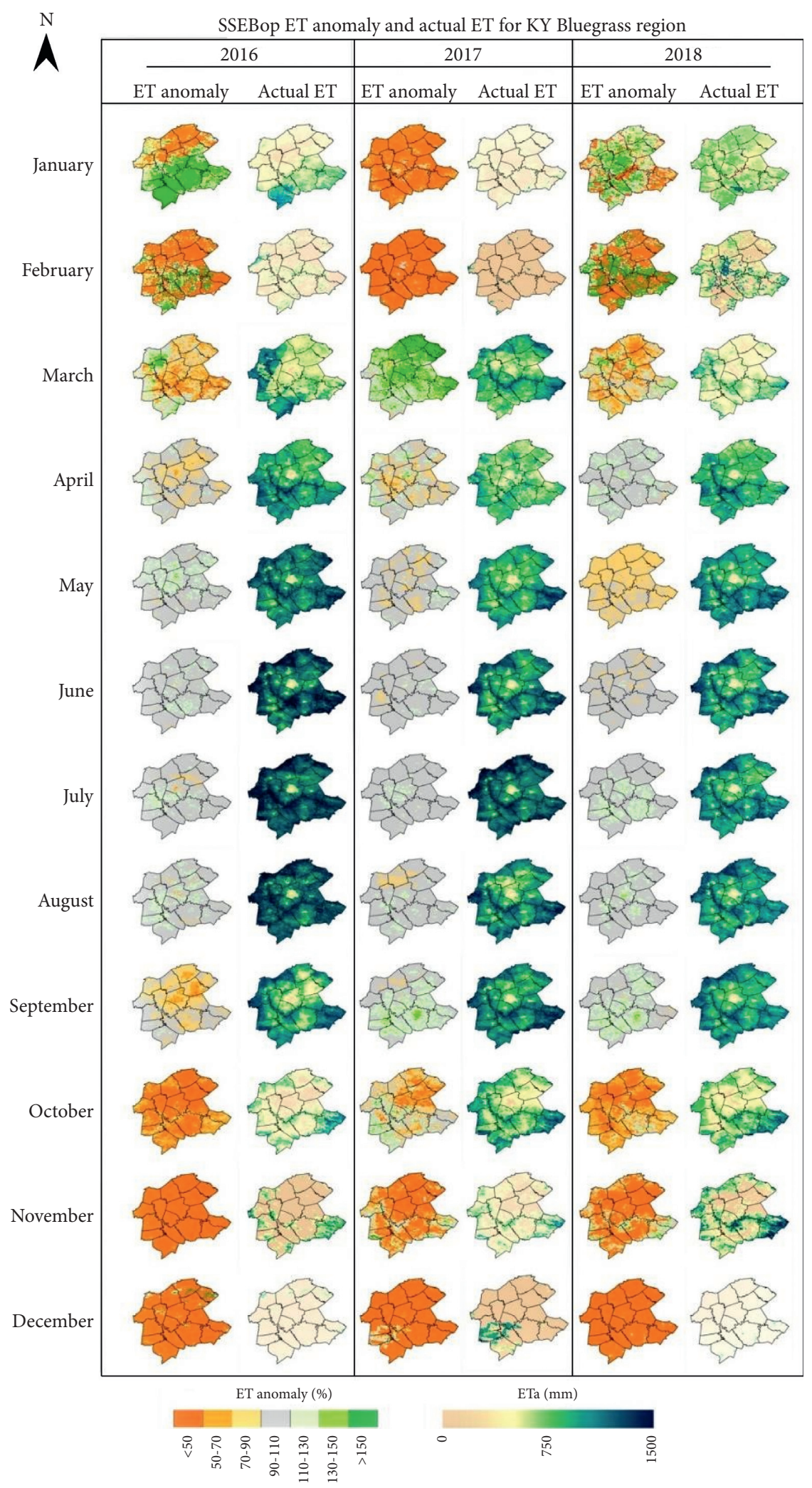

FIGURE 5: Spatial distribution of the remotely sensed actual ET $\left(E T_{a}\right)$ and anomalies at the eddy covariance site and surrounding counties from 2016 to 2018. This map includes the 17-county area known as the "Bluegrass" region of Kentucky and they have similar vegetative features, featuring large pastureland and other agricultural lands. The counties are Anderson, Bourbon, Boyle, Clark, Estill, Fayette, Franklin, Garrard, Harrison, Jessamine, Lincoln, Madison, Mercer, Nicholas, Powell, Scott, and Woodford. The area represents $11,070 \mathrm{~km}^{2}$. Significantly lower than average ET (dry conditions) is identified with orange color. Higher than average ET is identified with green color. Maps showing ET anomalies are shown on the left side of each panel. Anomaly is computed as a deviation between average values of ET of any given year from the historical mean (2000 to 2017). 


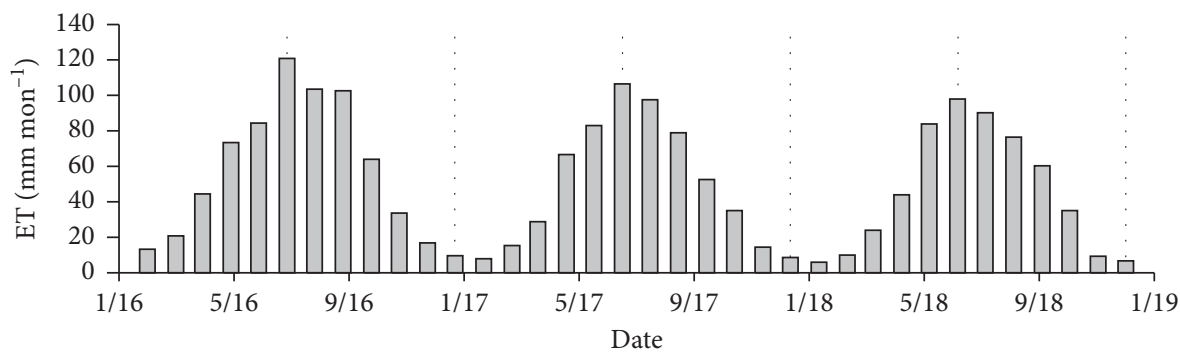

(a)

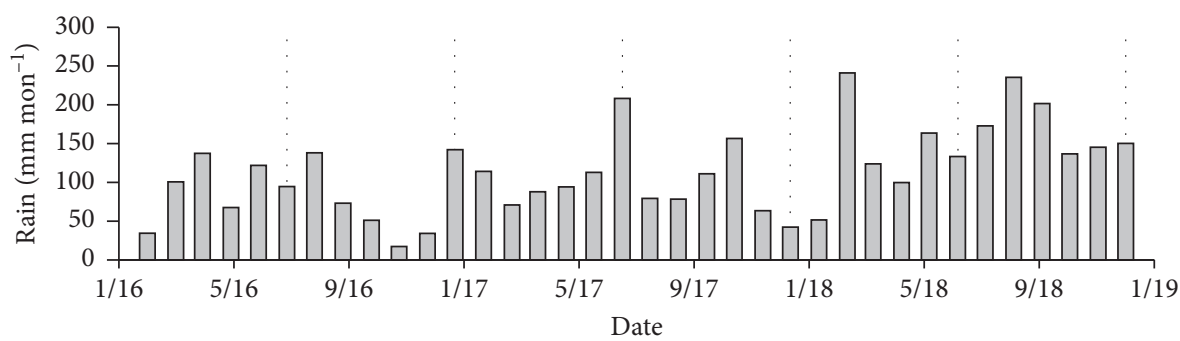

(b)

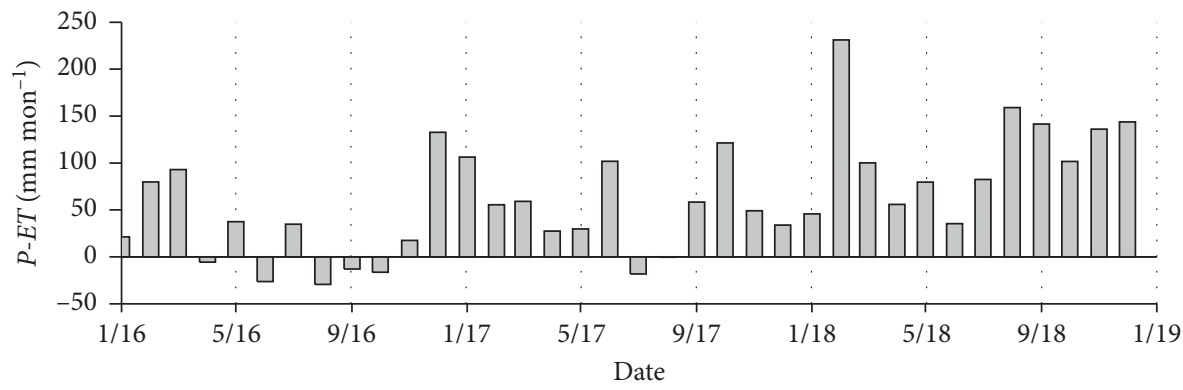

(c)

Figure 6: Monthly ET anomaly (defined here as P-ET) during 2016-2018, where P is precipitation. The monthly $P$-ET variation is controlled by precipitation exhibiting positive $(P>$ ET) and deficit $(P<$ ET). Precipitation data were obtained from the nearby $(<2$ miles $)$ Kentucky Mesonet weather station.

as drought and flooding, and thereby improve response capacity.

\section{Conclusion}

For this study, we examined and evaluated the performance of SSEBop model using direct, in situ ET eddy flux measurements at a managed pastureland in north central Kentucky between 2016 and 2018. The model was chosen because it provides data products at spatial and temporal scales suitable for comparison with ET data. SSEBop overand underestimated ET with a mean difference of $5 \mathrm{~mm} \cdot \mathrm{month}^{-1}$ averaged over the three years (2016-2018). The comparison between direct flux ET measurement and modeled ET allowed seasonal characterization of EC trends at this managed pasture site. Seasonality was captured well; however, the model underestimated ET during winter months and overestimated it during summer months. These data showed the following:

(i) SSEBop anomaly maps provide relevant drought information that can be used by various practitioners, and it offers tools for managing and mitigating drought, which helps guide mitigation strategies.

(ii) The model's poor performance may not necessarily indicate the model's inaccuracy. One possible explanation for this is mismatched data on spatial scales on 1 point $(100 \mathrm{~m}$ fetch area) versus $1000 \mathrm{~m}$ fetch area.

(iii) The SSEBop at the pasture site demonstrated the model's efficacy, which enforces its value as a reliable proxy for precipitation and a valuable indicator of ET anomalies on a month-to-month scale; however, the model's validation in areas characterized by contrasting seasonal and year-to-year precipitation requires further testing and additional research.

This study supports the model's use as proxy variable for precipitation and as a viable method for monitoring and assessing ground moisture status (i.e., drought). The SSEBop model is less complex than other remote-based ET products (e.g., METRIC and MODIS) and it provides sufficient information for reliably assessing and monitoring droughts on shorter time scales (e.g., daily to monthly). [29]. 


\section{Data Availability}

The data used to support the findings of this study are available from the corresponding author upon request.

\section{Conflicts of Interest}

The authors declare that there are no conflicts of interest regarding the publication of this paper.

\section{Acknowledgments}

This work was supported by the USDA National Institute of Food and Agriculture Evans-Allen project (Accession no. 1008982).

\section{References}

[1] J. B. Fisher, F. Melton, E. Middleton et al., "The future of evapotranspiration: global requirements for ecosystem functioning, carbon and climate feedbacks, agricultural management, and water resources," Water Resources Research, vol. 53, no. 4, pp. 2618-2626, 2017.

[2] A. J. Teuling, M. Hirschi, A. Ohmura et al., "A regional perspective on trends in continental evaporation," Geophysical Research Letters, vol. 36, no. 2, 2009.

[3] K. E. Trenberth, J. T. Fasullo, and J. Kiehl, "Earth's global energy budget," Bulletin of the American Meteorological Society, vol. 90, no. 3, pp. 311-324, 2009.

[4] K. Wang and R. E. Dickinson, "A review of global terrestrial evapotranspiration: observation, modeling, climatology, and climatic variability," Reviews of Geophysics, vol. 50, p. RG2005, 2012.

[5] S. Wang, B. J. Fu, G. Y. Gao, X. L. Yao, and J. Zhou, "Soil moisture and evapotranspiration of different land cover types in the loess plateau, China," Hydrology and Earth System Sciences, vol. 16, no. 8, pp. 2883-2892, 2012.

[6] J. B. Fisher, K. P. Tu, and D. D. Baldocchi, "Global estimates of the land-atmosphere water flux based on monthly AVHRR and ISLSCP-II data, validated at 16 FLUXNET sites," Remote Sensing of Environment, vol. 112, no. 3, pp. 901-919, 2008.

[7] H. A. Cleugh, R. Leuning, Q. Mu, and S. W. Running, "Regional evaporation estimates from flux tower and MODIS satellite data," Remote Sensing of Environment, vol. 106, no. 3, pp. 285-304, 2007.

[8] R. G. Allen, L. S. Pereira, T. A. Howell, and M. E. Jensen, "Evapotranspiration information reporting: II. Recommended documentation," Agricultural Water Management, vol. 98, no. 6, pp. 921-929, 2011.

[9] K. Zhang, J. S. Kimball, R. R. Nemani, and S. W. Running, “A continuous satellite-derived global record of land surface evapotranspiration from 1983 to 2006," Water Resources Research, vol. 46, no. 9, p. W09522, 2010.

[10] P. A. Solignac, A. Brut, J.-L. Selves et al., "Uncertainty analysis of computational methods for deriving sensible heat flux values from scintillometer measurements," Atmospheric Measurement Techniques, vol. 2, no. 2, pp. 741-753, 2009.

[11] D. Baldocchi, “Breathing' of the terrestrial biosphere: lessons learned from a global network of carbon dioxide flux measurement systems," Australian Journal of Botany, vol. 56, no. 1, p. 1, 2008.

[12] P. J. Vaughan, T. J. Trout, and J. E. Ayars, “A processing method for weighing lysimeter data and comparison to micrometeorological ETo predictions," Agricultural Water Management, vol. 88, no. 1-3, pp. 141-146, 2007.

[13] D. D. Baldocchi, "Assessing the eddy covariance technique for evaluating carbon dioxide exchange rates of ecosystems: past, present and future," Global Change Biology, vol. 9, no. 4, pp. 479-492, 2003.

[14] M. C. Anderson, R. G. Allen, A. Morse, and W. P. Kustas, "Use of Landsat thermal imagery in monitoring evapotranspiration and managing water resources," Remote Sensing Of Environment, vol. 122, pp. 50-65, 2012.

[15] G. R. Diak, J. R. Mecikalski, M. C. Anderson et al., "Estimating land surface energy budgets from space: review and current efforts at the university of Wisconsin-Madison and USDAARS," Bulletin of the American Meteorological Society, vol. 85, no. 1, pp. 65-78, 2004.

[16] Q. Mu, M. Zhao, and S. Running, MODIS Global Terrestrial Evapotranspiration (Et) Product (NASA MOD16A2/A3) Collection 5. Nasa headquarters, Numerical Terradynamic Simulation Group Publications, Washington, DC, USA, 2013.

[17] A. Irmak, I. Ratcliffe, P. Ranade et al., "Estimation OF land surface evapotranspiration with a satellite remote sensing procedure," Great Plains Research, vol. 21, pp. 73-88, 2011.

[18] W. P. Kustas, J. M. Norman, M. C. Anderson, and A. N. French, "Estimating subpixel surface temperatures and energy fluxes from the vegetation index-radiometric temperature relationship," Remote Sensing of Environment, vol. 85, no. 4, pp. 429-440, 2003.

[19] G. B. Senay, M. Schauer, M. Friedrichs, N. M. Velpuri, and R. K. Singh, "Satellite-based water use dynamics using historical landsat data (1984-2014) in the southwestern United States," Remote Sensing of Environment, vol. 202, pp. 98-112, 2017.

[20] R. K. Singh and G. B. Senay, "Comparison of four different energy balance models for estimating evapotranspiration in the midwestern United States," Water, vol. 8, p. 9, 2016.

[21] American Institute of Aeronautics and Astronautics, Guide For the Verification And Validation Of Computational Fluid Dynamics Simulations (AIAA G-077-1998 (2002)); Computational Fluid Dynamics Committee, American Institute of Aeronautics and Astronautics, Inc., Washington, DC, USA, 1998.

[22] G. B. Senay, S. Bohms, R. K. Singh et al., "Operational evapotranspiration mapping using remote sensing and weather datasets: a new parameterization for the SSEB approach," JAWRA Journal of the American Water Resources Association, vol. 49, no. 3, pp. 577-591, 2013.

[23] M. E. Jensen, R. D. Burman, and R. G. Allen, Evapotranspiration and Irrigation Water Requirements, p. 360, ASCE, Reston, VI, USA, 1990.

[24] Web Soil Survey Available online: "https://websoilsurvey.sc. egov.usda.gov/App/WebSoilSurvey.aspx" lo "https://websoils urvey.sc.egov.usda.gov/App/WebSoilSurvey.aspx" \h https:// websoilsurvey.sc.egov.usda.gov/App/WebSoilSurvey.aspx, 2019.

[25] R. G. Allen, L. S. Pereira, D. Raes, and M. Smith, "Crop evapotranspiration-guidelines for computing crop water requirements," Fao Irrigation and Drainage Paper, vol. 56, 1998.

[26] R. R. McShane, K. P. Driscoll, and R. Sando, "A review of surface energy balance models for estimating actual evapotranspiration with remote sensing at high spatiotemporal resolution over large extents," Scientific Investigations Report 2017-5087, vol. 19, 2017.

[27] X. Huang, Y. Hao, Y. Wang et al., "Partitioning of evapotranspiration and its relation to carbon dioxide fluxes in Inner 
Mongolia steppe," Journal of Arid Environments, vol. 74, no. 12, pp. 1616-1623, 2010.

[28] G. B. Senay, M. Friedrichs, R. K. Singh, and N. M. Velpuri, "Evaluating Landsat 8 evapotranspiration for water use mapping in the Colorado River Basin," Remote Sensing of Environment, vol. 185, pp. 171-185, 2016.

[29] G. B. Senay, N. M. Velpuri, S. Bohms et al., "Drought monitoring and assessment: remote sensing and modeling approaches for the famine early warning systems network," Hydro-Meteorological Hazards, Risks and Disasters, vol. 32, 2015. 